\title{
COLABORANDO NA TRAJETÓRIA DE SUPERAÇÃO EM SAÚDE MENTAL: GRUPO DE OUVIDORES DE VOZES
}

\author{
COLLABORATING IN THE TRAJECTORY OF RECOVERY IN MENTAL HEALTH: \\ HEARING VOICE GROUP
}

\section{CLARISSA MENDONÇA CORRADI-WEBSTER}

EDUARDO AUGUSTO

LEÃO

\section{LÍVIA SICARONI} RUFATO

Faculdade de Filosofia,

Ciências e Letras

de Ribeirão Preto -

Universidade de São Paulo,

Ribeirão Preto, SP, Brasil

Recebido em: 29/05/2018

Aprovado em: 18/06/2018
RESUMO: A experiência de ouvir vozes é comum na população em geral e muito encontrada em usuários de serviços de saúde mental. Tradicionalmente, 0 tratamento psiquiátrico concentra seus esforços na eliminação destas, dando pouca atenção para a experiência em si. Mesmo com 0 uso de medicamentos, muitas pessoas continuam a ouvir vozes e não encontram espaço para conversar e refletir sobre esta vivência. 0 objetivo deste artigo é descrever a experiência de trabalho com um Grupo de Ouvidores de Vozes e analisar como ouvidores vivenciam o fenômeno das vozes e a experiência com o grupo. Foi realizado relato de experiência de proposição e participação de um Grupo de Ouvidores de Vozes e conduzida análise temática de 10 relatos de memória de encontros grupais. 0 grupo descrito é aberto, acontece semanalmente e tem uma hora de duração. Conta com a participação de ouvidores e profissionais. Os ouvidores mais antigos no grupo responsabilizam-se pela realização do contrato grupal. Nos encontros são compartilhados os relacionamentos com as vozes, desde o relato de suas características, até as estratégias que vão sendo desenvolvidas para melhorar o relacionamento com elas. 0 grupo também foi apontado pelos ouvidores com um espaço de construção de redes de apoio, para além dos momentos dos encontros grupais. Para os profissionais, tem colaborado para se aproximarem das experiências dos usuários do serviço, auxiliando-os a serem agentes que colaboram na trajetória de superação dos ouvidores

PALAVRAS-CHAVE: saúde mental; superação; ouvidores de vozes.
ABSTRACT: The experience of hearing voices is common in the general population and is very common among users of mental health services. Traditionally, psychiatric treatment focused its efforts on eliminating these, paying little attention to the experience itself. Even with the use of medication, many people continue to hear voices and do not find space to talk and reflect on this experience. The purpose of this article is to describe the experience of working with a Hearing Voices Group and to analyze how the participants live with the voices phenomenon and their experiences with the group. An experience report was carried out regarding the proposal and participation of a Hearing Voices Group and thematic analysis of 10 memory reports of group meetings was conducted. The described group is open, takes place weekly and is of one-hour duration, with people with this experience and professionals participating. The people with this experience that had been in the group longer are responsible for performing the group contract. In the meetings, the relationships with the voices are shared, from the reporting of their characteristics to the strategies that are being developed to improve the relationship with them. The group was highlighted by the people with this experience as a space to construct support networks, beyond the moments of the group meetings. For the professionals, the group helped them to get closer to the experiences of the users of the service, helping them to be agents that collaborate in the trajectory of recovery of the people with this experience.

KEYWORDS: mental health; recovery, hearing voices. 


\section{INTRODUÇÃO}

A experiência de ouvir vozes parece ser comum na população em geral considerando que estudo de revisão aponta que 9,4\% referem já ter vivenciado este fenômeno. Entre crianças e adolescentes esta é ainda mais prevalente, havendo uma diminuição desta vivência com o envelhecimento (Maijer, Begemann, Palmen, Leucht, \& Sommer, 2018). Segundo Baker (2009), apenas uma em três pessoas que ouvem vozes tornam-se pacientes psiquiátricos e duas em três conseguem lidar com essa experiência sem qualquer intervenção médica.

No mundo ocidental, a experiência de ouvir vozes vem sendo tradicionalmente manejada pela psiquiatria, que a descreve como um sintoma conhecido como alucinação auditiva (Corradi-Webster, Leão, \& Santos, 2017). É uma experiência muito comum entre pessoas que recebem o diagnóstico de esquizofrenia, mas também pode acontecer com pessoas com outros diagnósticos, como transtorno dissociativo, transtorno de personalidade borderline e depressão com sintomas psicóticos. Nestas situações, os ouvidores relatam sofrimento por conviver com estas vozes, que muitas vezes são depreciativas e raivosas, além de perturbarem o dia a dia do ouvidor, que sente dificuldades em manter suas atividades por se ocupar com as vozes. Esta experiência também aparece associada à maior estigmatização, isolamento, angústia e pior prognóstico (De Jager et al., 2016). O tratamento psiquiátrico oferecido visa à remissão deste sintoma por meio do uso de medicamentos antipsicóticos.

Apesar do grande investimento em medicamentos que são prescritos, a fim de interromper esta experiência, muitas pessoas relatam continuar ou- vindo vozes. Isto acontece por diferentes motivos, dentre eles a opção por descontinuar o uso dos medicamentos, buscando evitar os efeitos colaterais indesejados, ou pela persistência das vozes, mesmo com o uso do medicamento. Baker (2009) aponta que, dentre aqueles que se tornam pacientes psiquiátricos e fazem uso de antipsicóticos, cerca de 30\% continuam ouvindo vozes.

Além disto, muitos ouvidores questionam o discurso psiquiátrico, que compreende esta experiência como sintoma de um adoecimento. Atribuem diferentes significados para estas experiências, utilizando para isto de outros discursos. Um deles seria o discurso religioso que, para alguns ouvidores, aborda esta vivência como sendo algo espiritual. Outro discurso seria o psicológico, que apresentaria elementos para compreender as vozes como respostas a traumas em idades precoces. Neste sentido, Romme, Escher, Dillon, Cortens e Morris (2009) descrevem que $70 \%$ das pessoas que ouvem vozes já passaram por algum tipo de trauma, seja este abuso sexual ou físico, negligência, stress ou situações que envolvam grande insegurança durante fases do desenvolvimento precoce do indivíduo (infância e adolescência).

Partindo da premissa de que há descrições alternativas ao discurso psiquiátrico para o fenômeno do ouvir vozes, surgiu primeiramente na Holanda e posteriormente no Reino Unido o Movimento dos Ouvidores de Vozes (Minelli, 2017). Este Movimento teve início em 1980 a partir da vivência do psiquiatra holandês Marius Romme com sua paciente ouvidora de vozes, Patsy Hage. Patsy estava em busca de formas de conviver com as suas vozes de forma a retirar esse fenômeno do campo da anormalidade e dividir a 
experiência com outras pessoas. Patsy fez um questionamento a Marius que mudou o modo como compreendia o fenômeno das vozes. Ela perguntou: "se você acredita em Deus, que é algo que nunca viu, ouviu ou sentiu, por que minhas vozes, que de fato ouço, seriam então menos reais do que sua crença em Deus?". Com esta questão em mente, Romme passou a dar mais legitimidade para a experiência de ouvir vozes, mostrando mais curiosidade a respeito destas e buscando conhecer os sentidos destas vozes para os ouvidores. Ao conversar e observar ouvidores, foi percebendo que reduzir as vozes a um fenômeno psicopatológico não era sempre benéfico às pessoas, não as auxiliando no aprendizado de lidar com estas. Para muitos ouvidores, as práticas mais efetivas seriam aquelas que davam suporte aos indivíduos por meio da compreensão do significado que este dava às vozes, oferecendo apoio para que mudassem a relação estabelecida com elas e promovendo o encontro entre pares, com o objetivo de também lidar com o isolamento e estigma (Corstens, Longden, McCarthy-Jones, Waddingham, \& Thomas, 2014).

Nesta mesma época, vinha crescendo internacionalmente um movimento de usuários de serviços de saúde mental que não aceitavam ser posicionados como doentes e que questionavam o tratamento tradicional, que era baseado em uma visão de recuperação clínica (clinical recovery) que buscava a total remissão dos sintomas e o retorno ao funcionamento anterior ao adoecimento. Esta visão era percebida por eles como algo que construía sentimentos de fracasso e que limitava suas vidas, já que ficavam centrados na incessante busca de eliminar os sintomas, uma vez que continuavam sentindo e vivenciando muitos destes. Propunham uma visão alternativa, nomeada de superação pessoal (personal recovery), que dizia respeito ao indivíduo viver uma vida cheia de sentidos e satisfação, independentemente do desaparecimento dos sintomas (Miranda, Pimentel, \& Villares, 2014; Slade, 2010).

Assim, as discussões propostas por Romme e Patsy sobre a construção de novos sentidos para o fenômeno de ouvir vozes iam na mesma direção que o paradigma da superação pessoal, tornando o movimento dos ouvidores de vozes como um dos mais proeminentes braços deste novo paradigma em saúde mental (De Jager et al., 2016). Romme et al. (2009) descrevem que a superação (personal recovery), a partir da prática com grupos de ouvidores de vozes, significa "tomar a vida de volta com as próprias mãos" e encontrar outros caminhos que não estejam marcados pelo sistema biomédico tradicional. As ideias que constroem esse conceito estão baseadas, primordialmente, nesse reestabelecimento da vida em suas diferentes dimensões. Após entrevistar mais de 300 ouvidores de vozes, Romme e Escher (1997) compreenderam que estas pessoas passavam por três fases em direção à superação: (a) surpresa, que envolve sentimentos iniciais de choque pelas novas experiências, a sensação de estar sobrecarregado com as vozes e as inúmeras tentativas de tirar as vozes da cabeça; (b) organização, em que o indivíduo começa a usar algumas estratégias em relação ao manejo de suas vozes, colocando limites para as interações; (c) estabilização, em que o ouvidor passa a integrar as vozes à sua vida, reconhecendo-as como parte de si e deixando de focar na eliminação destas.

O movimento dos ouvidores de vozes foi ganhando força, visando à construção de novas relações com o fenômeno de ouvir vozes, não se cen- 
trando no discurso psiquiátrico e tendo como um de seus princípios encontrar novas e melhores formas de ajudar os ouvidores na relação com as vozes, partindo da concepção de que pessoas diferentes atribuem significados diferentes para suas experiências (Baker, 2009). Desta colaboração entre usuários de serviços, profissionais e pesquisadores, estabeleceu-se uma rede para facilitar a criação de grupos de suporte de pares de ouvidores de vozes, promovendo o encontro entre estes. Esta rede internacional foi nomeada de The International Hearing Voices Network - INTERVOICE (De Jager et al., 2016) e organiza informações sobre Grupos de Ouvidores de Vozes em mais de 30 países (Intervoice, 2018).

O movimento dos ouvidores de vozes coloca alguns valores como centrais para o trabalho nesta direção, orientando grupos de ouvidores (Corradi-Webster et al., 2017; Corstens et al., 2014). O primeiro deles diz respeito a tratar de modo normalizado o fenômeno de ouvir vozes, como sendo parte natural da experiência humana. Ao considerar as vozes como respostas a circunstâncias emocionais, sociais e relacionais, e não como aberrações ou anormalidades, todas as pessoas poderiam ser potenciais ouvidores de vozes, diminuindo assim o estigma que vem muitas vezes associado ao diagnóstico psiquiátrico, colaborando também para que a pessoa planeje a sua vida com as vozes, sem ter que se concentrar em eliminá-las. O segundo valor defendido pelo movimento coloca que devem ser respeitados os diferentes significados atribuídos ao fenômeno, sem privilegiar um como verdade. Nesta mesma direção, o terceiro valor aponta que o ouvidor deve ser incentivado a encontrar seu próprio significado para as vozes, sendo os grupos de pares espaços ri- cos para a exploração de diferentes compreensões sobre o tema. O quarto valor compreende que, na maioria das vezes, as vozes podem ser compreendidas nas narrativas de vida dos ouvidores, sendo iniciadas e mantidas por eventos que vulnerabilizaram o indivíduo. Os ouvidores parecem se sentir mais fortalecidos ao entenderem estas vozes como relacionadas a eventos de sua vida do que como experiências aleatórias e arbitrárias. O quinto valor postula que o processo de aceitar as vozes como uma experiência real que pode ser manejada com sucesso é geralmente percebido pelo ouvidor como de mais ajuda do que as tentativas de eliminá-las. O sexto valor destaca a importância do suporte de pares para ajudar as pessoas a dar sentido e a lidar com as vozes.

O número de grupos de ouvidores de vozes tem aumentado, reunindo-se em serviços de saúde mental, em espaços comunitários e virtuais. Estes vêm se mostrando importantes para os ouvidores, principalmente para aqueles que fazem uso de medicamentos e continuam ouvindo vozes (Corradi-Webster et al., 2017). São espaços onde as pessoas podem compartilhar suas experiências, ter informações sobre o tema e desenvolver estratégias para lidar com as vozes (Ngo Nkouth, St-Onge, \& Lepage, 2010). Pesquisando um grupo virtual de ouvidores de vozes, Barros e Serpa (2017) identificaram que os temas mais abordados nestes foram as experiências com o uso de medicamentos, estratégias para diminuir o impacto das vozes, problemas no relacionamento com a família e sentidos sobre a audição de vozes. Os autores destacam que as mídias sociais têm sido úteis para auxiliar ouvidores a se relacionarem com pares e com suas vozes, minimizando o sofrimento psíquico. Os grupos comunitários 
também têm aumentado nos últimos anos. São geralmente compostos por experts pela experiência (ouvidores de vozes e familiares) e experts pela profissão (médicos, psicólogos, pesquisadores, enfermeiros, ativistas, dentre outros). Estes trabalham em parceria, propondo alternativas à compreensão hegemônica psiquiátrica dada à experiência de ouvir vozes, além de desenvolverem formas de enfrentamento e superação, buscando promover os direitos humanos dos ouvidores de vozes e garantindo que estes sejam posicionados como experts da experiência vivida (Corstens et al., 2014).

Além dos valores já descritos anteriormente, a literatura traz outras sugestões relacionadas ao grupo. Beavan, De Jager e Santos (2016) apontam que, para os participantes do grupo, este não deve ser prescritivo, já que o contexto em que as vozes aparecem é diferente para cada pessoa, além de que cada um se beneficia de uma estratégia. Entretanto, reconhecem que o compartilhamento de experiências positivas no manejo das vozes é algo que colabora com o grupo, tanto instilando a esperança como contribuindo para que os participantes experimentem outras formas de lidar com elas. De Jager et al. (2016) destacam que o fato de estar entre pares, refletindo sobre dificuldades comuns e ouvindo histórias de vida, parece também impactar no modo como se relacionam com outras pessoas, tornando-se mais empáticos e auxiliando-os a comunicarem suas emoções. Nesta mesma direção, Corradi-Webster, Santos e Leão (2017) relatam que os ouvidores reclamam por não ter com quem compartilhar a experiência de ouvir vozes. Afirmam que familiares e amigos não compreendem a experiência e que também evitam conversar sobre isso com médicos, pois sabem que este relato vem geralmente acompanhado de aumento na medicação, o que tentam evitar, devido aos efeitos colaterais. Assim, colocam que o Grupo de Ouvidores de Vozes é um espaço único para conversarem abertamente sobre uma experiência que lhes toma tanta energia e influencia tanto em suas vidas. Beaven et al. (2016) encontraram que $75 \%$ dos participantes de grupos de ouvidores sentiam-se mais compreendidos, $68 \%$ sentiram-se menos isolados e $68 \%$ sentiram-se melhor consigo mesmo após participarem dos grupos. Observa-se então que um dos maiores benefícios do grupo é a criação de um espaço de acolhimento e troca entre pares.

Para Beaven et al. (2016), a participação em Grupos de Ouvidores de Vozes traz transformações muito significativas, por auxiliar a aumentar a autoconfiança, dar suporte ao empoderamento e elevar a autoestima. Em revisão de literatura realizada pelas autoras, elas identificaram que esta participação diminui a sensação de isolamento e aumenta a compreensão e aceitação da experiência de ouvir vozes. É descrito também que pode reduzir a busca por cuidados em emergências psiquiátricas, diminuindo o impacto do tratamento psiquiátrico e da estigmatização e facilitando que sigam com atividades do cotidiano, como o trabalho e a escola.

De Jager et al. (2016) também identificaram em suas entrevistas que, com o passar do tempo, as pessoas que participavam dos grupos de ouvidores iam se sentindo mais fortalecidas. As autoras apontam que isto pode estar relacionado às novas descrições de self que são oferecidas pelo grupo, uma vez que o ouvidor deixa de ser posicionado como doente em busca de recuperação. Os valores 
propostos pelo movimento seriam recursos discursivos que auxiliariam a ressignificar a experiência de ouvir vozes, possibilitando que outras narrativas de si fossem construídas. Para muitos ouvidores, as vozes começam a ser compreendidas como parte de sua subjetividade e entendem que compreendê-las melhor seria como conhecer mais a si mesmos.

É importante destacar que, embora o movimento normalize o fenômeno de ouvir vozes e busque diferentes alternativas para compreendê-lo e manejá-lo, não se orienta que as pessoas deixem o tratamento psiquiátrico. Entende-se que as pessoas devem ser informadas sobre todos os aspectos do tratamento e que o uso de antipsicóticos é uma opção individual que deve ser respeitada. Muitos ouvidores dizem que os medicamentos podem ser úteis porque reduzem a intensidade emocional e auxiliam a dormir. Entretanto, o medicamento é compreendido como uma das opções para lidar com possíveis ansiedades advindas da experiência de ouvir vozes, e não como algo necessário ao tratamento (Corradi-Webster et al., 2017). Mesmo que o ouvidor opte por continuar com a farmacoterapia, a literatura aponta que $37 \%$ dos participantes de grupos consideram que diminuíram a medicação (Beaven et al., 2016).

Considerando que a literatura vem apontando a importância do grupo de pares para pessoas que ouvem vozes e que esta perspectiva de trabalho ainda é nova na realidade brasileira, este artigo tem como objetivo descrever a experiência de trabalho de experts pela profissão com um Grupo de Ouvidores de Vozes realizado em um serviço comunitário de saúde mental e analisar como experts pela experiência vivenciam o fenômeno das vozes e a experiência com o grupo.

\section{MÉTODOS}

Para atingir os objetivos propostos, será realizado inicialmente um relato de experiência sobre a proposição e participação enquanto experts pela profissão em um Grupo de Ouvidores realizado em um Centro de Atenção Psicossocial de nível 3 (CAPS) de uma cidade de médio porte do interior do estado de São Paulo. O grupo relatado aqui teve início em abril de 2015, após os dois primeiros autores, psicólogos, terem contato com o Movimento de Ouvidores de Vozes por meio de Paul Baker, membro do INTERVOICE, na ocasião do I Congresso Internacional de Saúde Mental Escola Franca e Franco Basaglia, realizado em Ribeirão Preto e Campinas, interior de São Paulo. Este relato busca trazer elementos sobre a organização do grupo e sobre como os autores vêm percebendo o amadurecimento deste, após três anos de início.

Em seguida, serão analisados dados secundários, ou seja, a análise de 10 relatos de memória de encontros grupais ocorridos no ano de 2018. Estes relatos foram realizados por três estagiários do $5^{\circ}$ ano do curso de Psicologia, que fazem o treinamento profissional em saúde mental no CAPS e participam semanalmente dos encontros do Grupo de Ouvidores de Vozes desde fevereiro de 2018. Os relatos de memória foram inicialmente produzidos com o objetivo de apresentarem em supervisão o que ocorreu durante o encontro grupal. Como discutido por Silva et al. (2014), os relatos de memória são recursos potentes para supervisão, pois embora mais enxutos que a transcrição literal, conseguem reunir os principais conteúdos discutidos no encontro e preservam as experiências emocionais deste. 
A análise destes relatos foi realizada por meio da técnica de análise temática, seguindo os 5 primeiros passos propostos por Braun e Clarke (2006). Assim, a análise foi conduzida em seis fases: (a) familiarização com os dados por meio de leituras do material; (b) construção de códigos iniciais, identificando-se falas que eram relevantes ao objetivo do estudo e codificando sobre o que estas versavam; (c) construção de temas através da organização dos códigos; (d) revisão dos temas, buscando conhecer como estes se relacionavam com os códigos iniciais e com os dados como um todo e produção de mapas temáticos; (e) definição e nomeação dos temas.

\section{A EXPERIÊNCIA COM UM GRUPO DE OUVIDORES DE VOZES}

O Grupo de Ouvidores de Vozes relatado aqui teve início em abril de 2015 e foi implementado dentro do espaço físico de um Centro de Atenção Psicossocial de nível 3. Nesse CAPS encontrou-se a estrutura física necessária para a realização do grupo (como cadeiras e espaço coberto), além desse serviço configurar-se como local propício para que pessoas que ouvem vozes se disponibilizassem a falar a este respeito. Após pactuar com a gerência do serviço a permissão para realizar o grupo, a proposta foi apresentada na reunião de equipe e as dúvidas a respeito do que seria realizado foram sanadas. Questões relacionadas ao fenômeno de ouvir vozes eram corriqueiras dentro do serviço e a equipe muitas vezes sentia-se despreparada para lidar com essa questão. Assim, a proposta do grupo foi apresentada aos profissionais como uma estratégia complementar ao cuidado já oferecido por eles e não como um contraponto ao que eles já faziam.
O grupo é aberto e o convite não restrito apenas àqueles que se identificam como ouvidores mas, também, às pessoas que desejam conversar e ouvir a respeito desta temática. Todos os que se encontram no CAPS no momento do grupo, sejam familiares, profissionais, estagiários (estudantes de Psicologia, Enfermagem ou curso técnico de Enfermagem em estágio no CAPS) são convidados a participar do grupo. Um dos desafios dessa configuração refere-se ao fato de que, nos diferentes encontros, o grupo contava com membros diferentes, precisando de um tempo maior para que se formasse uma identidade enquanto grupo. Entretanto, alguns participantes foram vinculando-se à proposta e mantendo-se mais frequentes. Ainda assim, além dos integrantes que frequentam o grupo assiduamente, há sazonalidade de alguns participantes que estão em acolhimento no CAPS-III e que se interessam em participar de forma pontual. Esta diferença tem se mostrado enriquecedora, uma vez que a mescla entre alguns integrantes fixos e outros sazonais possibilitou manter sempre em aberto a construção de sentidos a respeito do fenômeno de ouvir vozes no grupo.

Os grupos têm em média uma hora de duração e contam com 12 a 20 participantes. Dentre os participantes, a maioria é ouvidores de vozes (experts pela experiência) e os outros são profissionais/estudantes (experts pela profissão) e pessoas que vão ao grupo por interesse em saber mais sobre o assunto. Qualquer pessoa pode se juntar ao grupo durante o encontro ou deixar este antes de seu término.

A cada início de grupo é averiguado se existe alguém ali que nunca participou do encontro e, nesse caso, é proposto que algum integrante que já tenha participado anteriormente ex- 
plique sobre em que consiste o grupo e como se dá o funcionamento deste. Faz-se o contrato grupal deixando claro que os sentidos trazidos por todos os integrantes devem ser validados como possíveis, mesmo que não haja concordância sobre eles. Compreende-se no grupo que ouvir vozes é um fenômeno natural do ser humano e que cada ouvidor é a autoridade máxima sobre os sentidos a respeito da experiência de ouvir suas vozes. Dessa forma, propõe-se escutar aquele que ouve vozes sem julgamentos, buscando compreender junto com ele sua experiência, ao invés de propor entendimentos a priori sobre o fenômeno. Essa apresentação do funcionamento do grupo possibilita que os integrantes construam um funcionamento grupal mais horizontal, acolhendo sem julgamento aquele que ouve vozes e dividindo esta experiência com os demais, além de fomentar uma atmosfera de curiosidade a respeito do tema.

Tal perspectiva de trabalho muitas vezes contrasta com a maneira como a relação paciente-profissional se estabelece nos serviços de saúde mental. Comumente, constrói-se uma relação em que o profissional é quem sabe o que se passa com o paciente e o avalia para apresentá-lo à verdade por trás da experiência vivida por ele. A horizontalidade do grupo pode inicialmente gerar certa frustração em alguns participantes, que buscam nesse espaço resposta dos profissionais para a experiência de ouvir vozes. Entretanto, o grupo como espaço de produção de sentidos instrumentaliza os participantes a construírem suas próprias verdades sobre o que vivenciam. Dessa forma, os ouvidores de vozes empoderados podem, com a ajuda dos pares e dos profissionais, produzir práticas mais efetivas para lidar com as vozes ao invés de serem apresentados a uma verdade única e universal (e por vezes ineficaz) a respeito deste fenômeno.

O grupo tem se consolidado como espaço para construir outros entendimentos a respeito das vozes e, portanto, espaço seguro para conversar a respeito destas sem julgamentos. Isso tem sido apontado pelos integrantes como sendo a característica mais importante da atividade. O estigma dificulta que o assunto seja abordado de forma livre dentro dos contextos da família e de saúde, que trazem normalmente um entendimento pronto (e rígido) do fenômeno como associado à patologia, refutando muitas vezes quaisquer entendimentos de outro tipo.

Com o passar dos encontros, o grupo foi alterando sua característica, amadurecendo. Participantes mais assíduos ao grupo tornaram-se lideranças dentro e fora do espaço do encontro grupal. Esses participantes começaram a oferecer uma escuta de quem investigou sua própria experiência de ouvir vozes e podem agora também oferecer suporte a seus pares que se apresentam como ouvidores pela primeira vez, tornando-se assim experts pela experiência. Esse novo posicionamento teve para os experts um valor muito importante. Diferentemente de outros aparatos de saúde mental, recuperar-se do sofrimento causado pelas vozes não resulta em medidas que o retirem de seu espaço de cuidado. $\mathrm{O}$ expert pela experiência continua como membro a ser ajudado em situação oportuna, mas agora adquire também papel fundamental no apoio aos membros menos experientes. Estar posicionado como alguém que sabe a respeito daquele assunto pareceu auxiliar essas pessoas a não só ajudarem os outros, mas também a se sentirem mais seguros por poderem falar com autoridade sobre a própria experiência. Deixaram a posição pas- 
siva tradicional de quem fica à mercê da conduta de profissionais que buscam eliminar os sintomas e passaram a ser posicionados como pessoas que têm conhecimento e experiência em relação ao que vivenciam e que podem ajudar a si mesmos e a outras pessoas.

O grupo também se faz como uma ferramenta importante de promoção de empoderamento àqueles participantes que se encontravam em tratamento no CAPS. Por diversas vezes, o grupo se mobilizou espontaneamente para discutir questões que emergiam a respeito da insatisfação de participantes com profissionais do serviço que eles consideravam que não os ouviam em suas necessidades. Assim, possibilitar que eles também fossem ouvidos e respeitados em suas opiniões por familiares e profissionais dentro e fora do grupo (e discutir estratégias para atingir este objetivo) tornou-se uma das preocupações dos participantes. $\mathrm{Na}$ mesma direção, para os profissionais do serviço, estar no grupo foi considerada uma condição de aprendizado a respeito da experiência dos ouvidores, e o relato destes é de que esta participação os auxiliava frente à cobrança de que trouxessem uma verdade única e universal a respeito da questão quando ela se apresentava em diferentes contextos profissionais. Para profissionais e estagiários, deixar esta postura de experts no assunto lhes abriu a possibilidade de construir relações com os ouvidores de parceria e aprendizado em busca de um suporte mais humanizado. Por compreender que o fenômeno de ouvir vozes é natural e humano, o grupo não pretende "curar" as pessoas eliminando as vozes. Entende que as vozes aparecem e desaparecem de forma natural, da mesma forma que podem se alterar com o passar do tempo. Dessa forma, o grupo se ocupa mais em tentar compreender quais as características das vozes e melhorar a relação com elas, do que de preveni-las ou eliminá-las. A experiência do grupo tem mostrado que, ainda que ouvir vozes seja algo muito presente na vida de algumas pessoas, normalmente estas sabem muito pouco sobre elas, provavelmente por um entendimento de que os esforços devem ser no sentido da eliminação e não da compreensão das vozes. O grupo é um espaço que ajuda a (re)construir sentidos sobre as vozes que são relatadas, investigando qual seu tom, qual o gênero destas, a idade, de onde elas vêm, em que momentos elas aparecem, quais seus nomes, dentre outros aspectos. Investigar essas características ajuda a pessoa que ouve a voz a construir uma identidade para essa voz, habilitando-a a pensar em novas maneiras de se relacionar com esta. Assim, aquele que ouve a voz se apropria da voz que também faz parte dele.

O grupo, além da característica terapêutica de criar um ambiente de cuidado e atenção ao sofrimento que acompanha a experiência de ouvir as vozes, possui uma característica de inclusão social, permitindo às pessoas que ouvem vozes terem um lugar de pertencimento no mundo. Muitos dos ouvidores que passaram pelo grupo relataram ter sempre se calado em relação à sua experiência, por acreditarem que eram únicos que tinham aquele tipo de vivência ou por temerem reações aversivas ao apresentarem a outros sua experiência de ouvir vozes. Poder garantir a estas pessoas um local em que elas possam falar sem sofrerem preconceitos a respeito de como vivenciam o ouvir vozes possibilitou que o sofrimento fosse reduzido e isso impactou no teor de algumas vozes que, frente a um contexto menos hostil à sua existência, também reduziam a hostilidade com o ouvidor. 


\section{RELACIONAMENTO COM AS VOZES E BENEFÍCIOS DO GRUPO}

Foi realizada análise temática de relatos de memória de dez encontros do Grupo de Ouvidores de Vozes e o material obtido foi organizado em três temas: apresentação do grupo; relacionamento com as vozes; benefícios do grupo.

Como descrito anteriormente, o Grupo de Ouvidores de Vozes é composto por experts pela experiência e experts pela profissão. Como o grupo é aberto, há a necessidade de se explicar seu objetivo e funcionamento a cada encontro. Assim, observou-se em todos os relatos que um tempo do encontro era utilizado para a apresentação do grupo. Na análise, observou-se que a explicação a respeito do funcionamento do grupo é geralmente feita por um expert pela experiência que se voluntaria no início do encontro. $\mathrm{O}$ grupo foi descrito pelos participantes como tendo como objetivo abrir espaço para se conversar sobre a vivência com as vozes. Interessante notar que em quase todas as apresentações foi dito que as vozes não somem, e que, portanto, é preciso desenvolver estratégias para diminuí-las e para lidar melhor com elas. Disseram também que o grupo tinha como objetivo auxiliar o ouvidor a compreender essa experiência e a criar uma rede de ajuda.

$\mathrm{Na}$ análise, observou-se que os participantes utilizaram grande parte do tempo grupal para compartilharem as últimas experiências com as vozes, descrevendo e analisando o relacionamento com as vozes. Contaram sobre as situações em que as vozes apareceram ou em que ganharam mais força, tanto em volume quanto em quantidade. Nos relatos analisados isto aconteceu principalmente após uma situação de conflito do ouvidor com algum fa- miliar, amigo ou, até mesmo, com desconhecido. Alguns participantes associaram mudanças ocorridas em suas vidas, como morte de familiares ou divórcio, com o surgimento ou agravamento das vozes. Outras situações pontuadas foram preocupações com familiares e a solidão. A troca de medicamentos e a busca pela dose adequada também foram levantadas.

Quase todos os relatos colocaram o ouvir vozes como uma experiência negativa. As vozes foram descritas como autoritárias e perversas, dando ordem para que matassem ou ferissem familiares e amigos, ou então para que se mutilassem e tirassem a própria vida. Foram descritas também como zombeteiras e provocadoras, humilhando-os e dizendo que eram incompetentes e inúteis. Frente a isto, relataram que as vozes os perturbavam e os deixavam confusos, atrapalhando suas rotinas, ficando nervosos e irritados. Não queriam seguir a ordem das vozes e começavam a desenvolver estratégias para isto. Algumas pessoas disseram sentir medo das vozes e, por isto, não gostavam de interagir com elas. Sentiam-se também discriminadas por terem essa experiência, já que é algo desconhecido pela maioria das pessoas não ouvidoras. Contaram que mesmo os familiares não compreendiam o que viviam e muitas vezes os culpabilizavam por isto, dizendo que era besteira ou fraqueza de caráter. Nos relatos analisados houve dois participantes que disseram ouvir vozes boas, que os ajudavam, deixando-os felizes. Os participantes presentes há mais tempo no grupo relataram a importância do grupo para auxiliá-los a conviver com as vozes, ao passo que os participantes novos geralmente trouxeram expectativas de que o grupo os ajudasse a eliminá-las. 
Durante os encontros foram compartilhadas várias estratégias para minimizar as vozes e para auxiliar a lidar com elas. A estratégia mais utilizada foi a busca por outras pessoas, seja para conversar sobre o ouvir vozes, seja para se sentirem seguros e distrair-se. O Grupo de Ouvidores foi colocado como fonte de apoio, além de relatar a busca por outros colegas usuários do serviço de saúde mental e profissionais deste. Foi também falado sobre estar próximo a crianças, como filhos e netos, a fim de sentirem conforto e poderem mudar o foco das preocupações.

Buscar distrair-se e tirar o foco da voz foi algo descrito em diferentes encontros como sendo um recurso. Dentre as atividades que auxiliavam, foram destacadas a caminhada, a leitura e o cantar hinos religiosos. Como disseram não ouvir vozes enquanto dormem, o sono também apareceu como sendo um recurso utilizado quando estavam muito incomodados com elas. $\mathrm{O}$ tratamento psiquiátrico foi colocado por alguns participantes como algo que ajuda, havendo relatos de melhora quanto a lidar com o sofrimento advindo das vozes após uso de medicamentos e de internação. Entretanto, os participantes relataram que a medicação não funcionava para erradicar as vozes. Ela ajudava a diminuí-las em algumas situações e colaborava para acalmá-los.

Com os relatos, observou-se que nos encontros são elencados vários benefícios em participar do Grupo de Ouvidores de Vozes. Este foi apontado como recurso importante para normalizar a experiência de ouvir vozes. Como não se sentiam compreendidos por não ouvidores externos ao grupo, perceberam neste uma oportunidade de terem a experiência e o sofrimento decorrentes dela legitimados por pessoas que também a vivenciavam ou que entendiam sobre ela. Também relataram que o grupo os auxiliava na busca por estratégias para lidar com as vozes, por possibilitar a troca entre os ouvidores e por compartilharem relatos de sucesso no uso de algumas destas estratégias. Com a participação no Grupo de Ouvidores perceberam que foi se criando uma rede de cuidados e de suporte que funcionava não apenas no momento em que o grupo estava todo junto, mas que podiam recorrer aos participantes deste para terem conversas privadas sobre dificuldades que estavam enfrentando. Relataram que esses benefícios impactaram em suas rotinas e subjetividades, diminuindo a discriminação.

\section{CONSIDERAÇÕES FINAIS}

Este artigo teve como objetivo descrever a experiência de experts pela profissão com a proposição e participação em um Grupo de Ouvidores de Vozes e analisar como experts pela experiência vivenciam o fenômeno das vozes e a experiência com o grupo.

O grupo descrito teve início há três anos, sendo realizado em um serviço comunitário de saúde mental. Conta com a participação de experts pela profissão e experts pela experiência. É um grupo aberto, realizado semanalmente, com uma hora de duração. No início, um expert pela experiência apresenta os objetivos do grupo e realiza o contrato grupal. Os participantes costumam usar os encontros para compartilharem e analisarem suas experiências com as vozes, pontuando estratégias que têm utilizado para melhorarem o relacionamento com elas.

O grupo tem sido relatado como um espaço privilegiado para conversarem sobre a temática das vozes, 
descrita pelos ouvidores como uma experiência sobre a qual geralmente não conseguem falar com amigos, familiares e profissionais. Ao compartilharem a experiência entre experts, percebem que esta passa a ser mais normalizada e que estratégias para lidar com elas passam a ser construídas. Essa experiência os empodera, ao posicioná-los como pessoas que podem desenvolver recursos para melhorar o relacionamento com as vozes. Além disto, o grupo proporciona a criação de uma rede de apoio que vai além do momento do encontro grupal. Os ouvidores passam a identificar em outros experts pela experiência o suporte de que precisam em momentos difíceis, buscando nos pares o conforto, o diálogo e o cuidado.

Para os experts pela profissão, o grupo tem se mostrado como uma oportunidade de se aproximarem das experiências relatadas em seu dia a dia de trabalho e, por conseguinte, dos usuários do serviço de saúde mental. Tradicionalmente, dá-se pouco espaço, nesses serviços, para a exploração dessas vivências, uma vez que o foco da psiquiatria tradicional se faz por meio da concentração dos esforços na eliminação das vozes. Como em muitas situações isto não é possível, profissionais tendem a se esquivar dessa conversa e a negarem parte importante da vida das pessoas às quais prestam cuidados.

Percebe-se que o Grupo de Ouvidores de Vozes tem se mostrado como um espaço importante no serviço de saúde mental para auxiliar os ouvidores na trajetória da superação pessoal, promovendo a esperança e a autonomia, auxiliando os ouvidores a buscarem recursos, apoiando a diversidade e construindo redes colaborativas e significativas.

\section{REFERÊNCIAS}

Baker, Pn (2009). The voice inside: a practical guide to coping with hearing voices. Lewis, Scotland: P\&P Press.

Barros, 0. C. \& Serpa, O. D. (2017). Ouvir vozes: um estudo netnográfico de ambientes virtuais para ajuda mútua. Physis: Revista de Saúde Coletiva, 27(4), 867-888.

Beavan, V., De Jager, A., \& Santos, B. (2016). Do peersupport groups for voice-hearers work? A small scale study of Hearing Voices $\mathrm{Ne}$ twork support groups in Australia. Psychosis, 9(1), 57-66. doi: 10.1080/17522439.2016.1216583

Braun, V. \& Clarke, V. (2006). Using thematic analysis in psychology. Qualitative Research in Psychology, 3(2), 77-101.

Corradi-Webster, C. M., Leão, E. A.s \& Santos, M. V. (2017). Construindo novos sentidos e posicionamentos em saúde mental: Grupo de Ouvidores de Vozes. In E. F. Rasera, K. Taverniers, \& Vilches-Álvarez (Orgs.), Construccionismo social en acción - Prácticas inspiradoras en diferentes contextos (pp. 167-193). Chagrin Falls, Ohio: Taos Institute Publications. ISBN: 9781938552557 Corstens, D., Longden, E., McCarthy-Jones, S., Waddingham R., \& Thomas, N. (2014). Emerging perspectives from the hearing voices movement: implications for research and practice. Schizophrenia Bulletin, 40, 285S294. doi: https://doi.org/10.1093/ schbul/sbu007

De Jager, A., Rhodes, Pry Beavan, V., Holmes, D., McCabe, K., Thomas, N., McCarthy-Jones, S. et al. (2016). Investigating the Lived Experience of Recovery in People Who Hear Voices. Qualitative Health Research, 26(10), 1-15. doi: $10.1177 / 1049732315581602$. 
Intervoice. (2018). The international Hearing Voices. Recuperado de http://www.intervoiceonline.org/

Maijer K, Begemann M. J. H., Palmen S. J. M. C., Leucht S., \& Sommer, I. E. C. (2018). Auditory hallucinations across the lifespan: a systematic review and meta-analysis. Psychological Medicine, 48(6), 879-888. doi: $10.1017 /$ S0033291717002367.

Miranda, A. M. P, Pimentel, F. A., \& Villares, C. C. (2014). "Anjos de uma asa só": processos de superação na esquizofrenia em um grupo de ajuda mútua. Nova Perspectiva Sistêmica, 23(48), 64-79.

Minelli, M. (2017). Cartografare paesaggi sonori. Un itinerario etnografico nella rete degli Uditori di Voci. Anuac - Rivista della Società Italiana di Antropologia Culturale, 6(2), 219-243.

Ngo Nkouth, B., St-Onge, M., \& Lepage, S. (2010). The group as a place of training and universality of the experience of voice-hearers. Groupwork, 20, 45-64. doi:10.1921/095182410X552693

Romme, M. \& Escher, S. (1997). Hearing voices. Schizophrenia Bulletin, 15(2), 209-216.

Romme, Mas Escher, S., Dillon, J., Cortens, D., \& Morris, M. (2009). Living with voices. 50 stories of recovery. Ross-on-Wye, UK: PCCS Books.

Silva, M. R., Barcellos, E. D., Sanchez, L. F., Steibel, D., Fernandes, P. P., Campezatto, P. V. M., Geremia, L., \& Klarmann, R. P. (2014). Registros de sessão terapêutica: relato, gravação ou transcrição? Considerações sobre as diferenças entre os registros. Psicologia Clínica, 26(2), 121-138. Recuperado de http://www.scielo.br/scielo. php? script $=$ sci_arttext $\&$ pid $=S 0103$ $-56652014000200008 \& \operatorname{lng}=$ en\&tlng $=\mathrm{pt}$
Slade, M. (2010). Personal Recovery and Mental Illness: A Guide for Mental Health Professionals. Cambridge, UK: Cambridge University Press.

\section{CLARISSA MENDONÇA CORRADI- WEBSTER}

Professora Doutora do

Departamento de Psicologia da

Faculdade de Filosofia, Ciências

e Letras de Ribeirão Preto -

Universidade de São Paulo;

Ribeirão Preto, SP.

\section{EDUARDO AUGUSTO LEÃO}

Mestrado em Psicologia pela

Faculdade de Filosofia, Ciências

e Letras de Ribeirão Preto -

Universidade de São Paulo;

Ribeirão Preto, SP.

\section{LÍVIA SICARONI RUFATO}

Mestrado em Psicologia pela

Faculdade de Filosofia, Ciências

e Letras de Ribeirão Preto -

Universidade de São Paulo;

Ribeirão Preto, SP. 